\title{
Outlook of IL-6 signaling blockade for COVID-19 pneumonia
}

\author{
Misato Hashizume
}

\begin{abstract}
In this review article, it is highlighted the implications of pleiotropic functions of interleukin-6 (IL-6) for one of the therapeutic options targeting for COVID-19. Moreover, it is discussed how real-world data and trials with IL-6 signaling blockade will be crucial in informing the development of new treatment for COVID-19 pneumonia. Given physiological roles of IL-6 in inflammatory conditions and the data from real world, IL-6 signal inhibitors, along with standard of care (SOC) treatment, might provide efficacy, offering the potential to treat COVID-19 in hospitalized populations more effectively than current SOC alone. Therefore, on-going and planned randomized placebo-controlled studies in combination with SOC and other therapeutics to assess safety and efficacy of IL-6 signal inhibitors in hospitalized patients with severe COVID-19 pneumonia will be warranted to address the high unmet need and burden of disease in this severely ill population.
\end{abstract}

Keywords: Interleukin-6, COVID-19 pneumonia, Cytokine release syndrome, Tocilizumab, Sarilumab, Siltuximab

\section{Background}

In this review article, it is highlighted that the implications of physiological role of interleukin-6 (IL-6), for one of the therapeutic options targeting for COVID-19 which is the acronym of "coronavirus disease 2019," are caused by a novel coronavirus strain (severe acute respiratory syndrome, SARS-CoV-2). Moreover, it is discussed how real-world data and trials with IL- 6 signaling blockade will be crucial in informing the development of new treatment for COVID-19 pneumonia.

\section{IL-6 and its therapeutic target}

IL-6 was found in 1973 as a soluble factor that is secreted by $\mathrm{T}$ cells and is important for antibody production by B cells [1]. Since its discovery more than 40 years ago, the IL- 6 pathway has emerged as a pivotal pathway involved in immune regulation in health and dysregulation in many diseases [2-4]. IL-6 is a pleiotropic proinflammatory multifunctional cytokine produced by a variety of cell types and has been shown to be involved in diverse physiological processes such as $\mathrm{T}$ cell activation; induction of acute phase proteins; stimulation of hematopoietic precursor cell growth and differentiation; proliferation of hepatic, dermal, and neural cells; bone metabolism; lipid metabolism; atherosclerosis; hepatoprotection; and fibrosis as shown in Fig. 1 [2-4]. Elevated tissue and serum levels of IL- 6 have been implicated in the disease pathology of several inflammatory and autoimmune disorders including multiple myeloma, Crohn's disease, rheumatoid arthritis (RA), Castleman disease, systemic juvenile idiopathic arthritis (sIIA), polyarticular juvenile idiopathic arthritis (pJIA), adult-onset Still's disease (AOSD), ankylosing spondylitis, psoriatic arthritis, systemic lupus erythematosus, giant cell arteritis (GCA), Takayasu arteritis (TAK), systemic sclerosis, and cytokine-release syndrome (CRS), and targeting of the IL-6 pathway has led to innovative therapeutic approaches for various rheumatic conditions such as RA, JIA, AOSD, GCA, TAK, and others such as Castleman disease or chimeric antigen receptor (CAR) $\mathrm{T}$ cell-induced CRS [2]. 


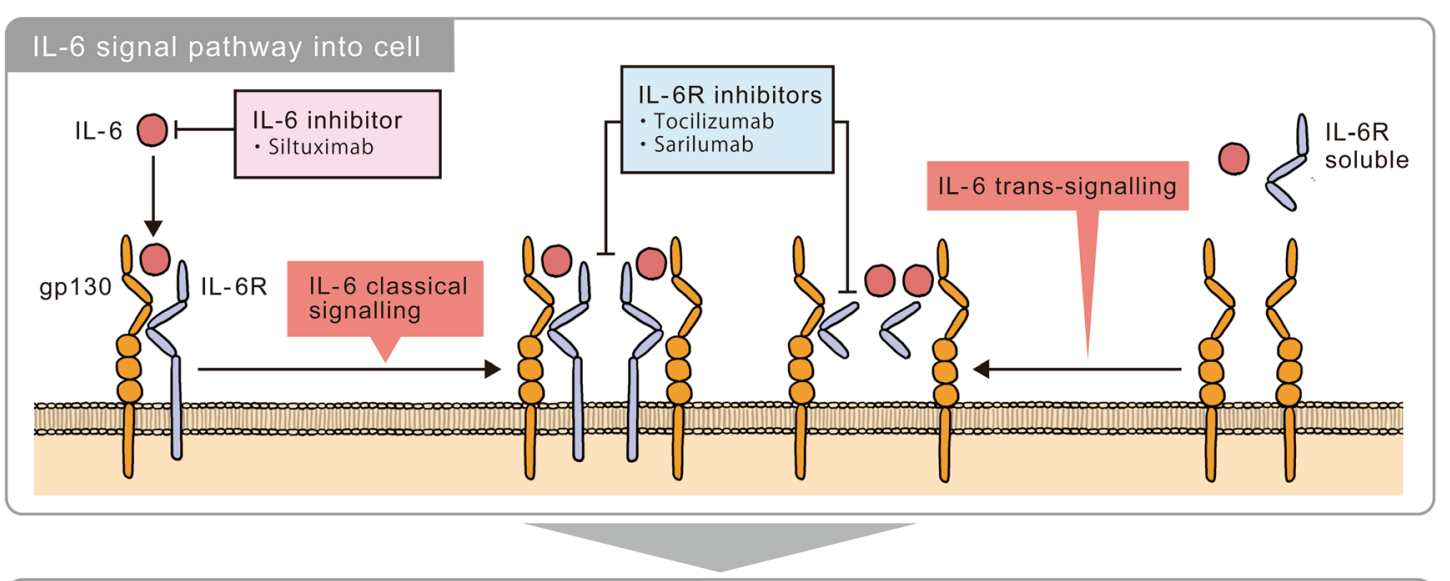

\section{Physiological roles of IL- 6 in cells and organs}

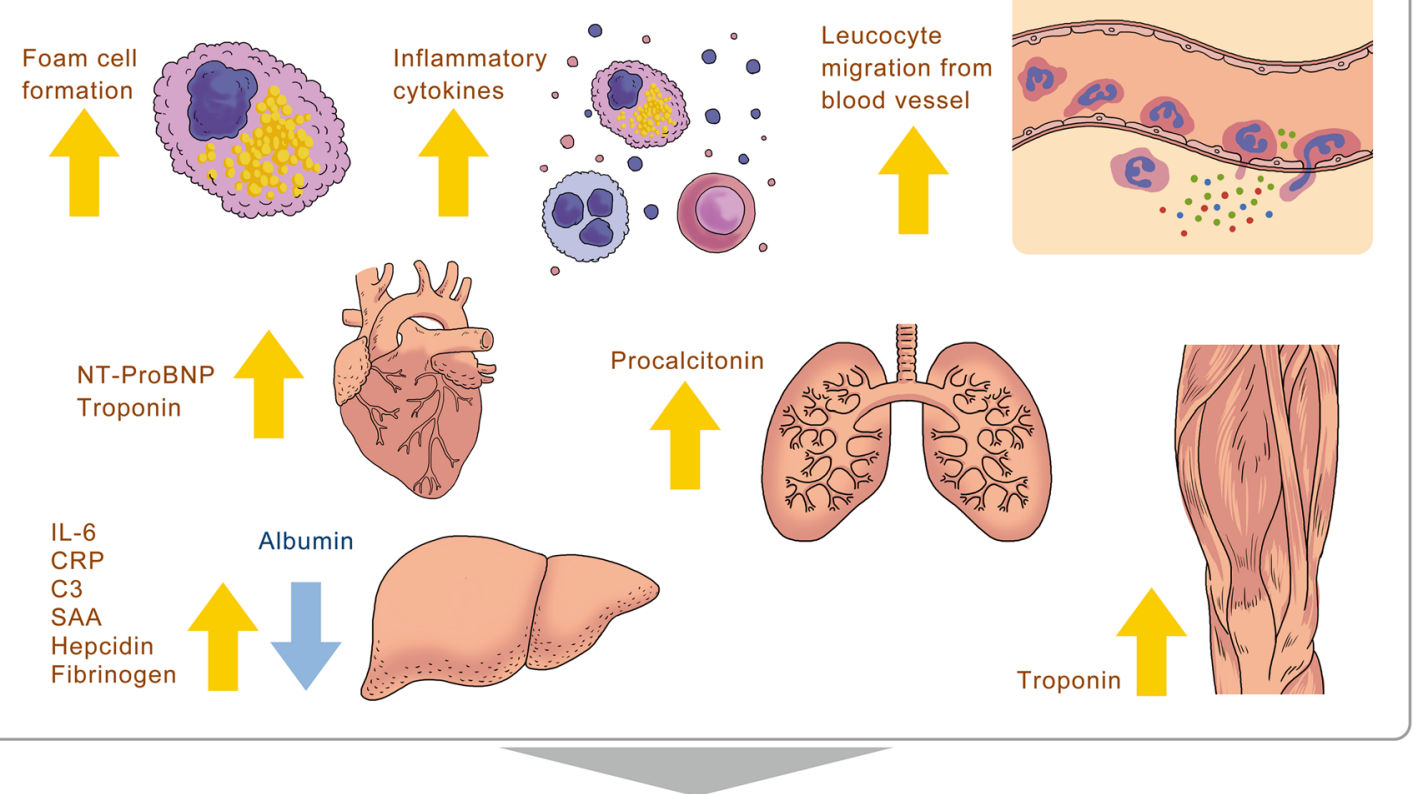

\section{COVID-19 related symptoms potentially driven by IL-6}

Laboratory marker abnormality CRP, Albumin, IL-6,

Procalcitonin,

Cardiac troponin,

Fibrinogen
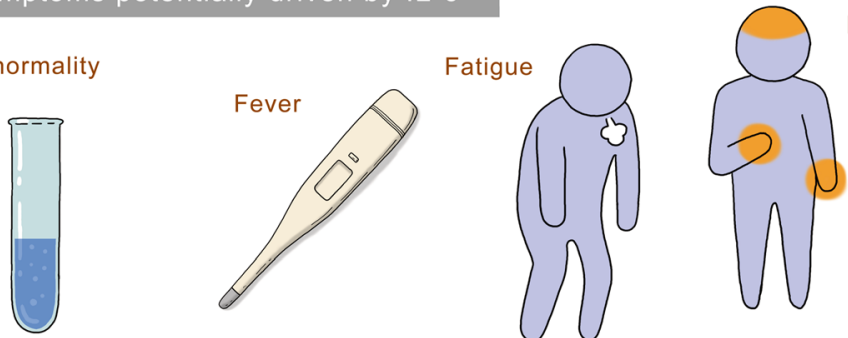

Pain

Vasculitis
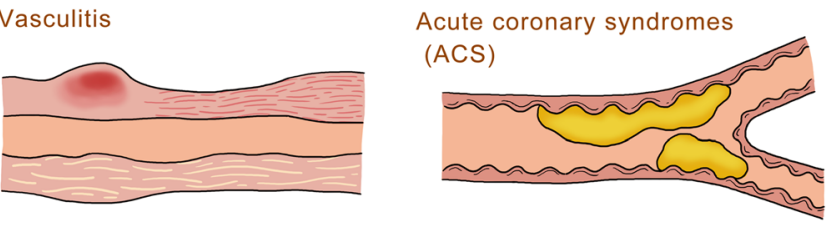

Acute respiratory distress syndrome (ARDS)

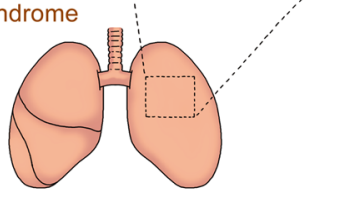

Fig. 1 (See legend on next page.) 
(See figure on previous page.)

Fig. 1 IL-6 involvement in COVID-19- key manifestations and hypothetical mechanisms. IL-6 binds to IL-6 receptor (IL-6R) and glycoprotein 130 (gp130) to form a hexametric complex which is associated with the classical and trans-signaling pathways. Pharmacological inhibitors of IL-6 signaling prevent IL-6 from binding to IL-6R by targeting either the cytokine itself or the receptor. IL-6 is well known to play various physiological roles in cells and organs. For example, in macrophage IL-6 induces foam cell formation [5] and in macrophage, B cell, T cell and neutrophil, IL-6 induces inflammatory cytokines [3, 4]. And IL-6 induces leucocyte migration from blood to organs $[3,6]$. IL-6 controls the level of NT-ProBNP and troponin [7]. In lung, IL-6 induces procalcitonin [8]. In liver, acute phase proteins including IL-6, CRP, C3, SAA, hepcidin, and fibrinogen are upregulated by IL-6, and albumin is downregulated by IL-6 [3, 4]

\section{Tocilizumab in cytokine-release syndrome of CAR T therapy}

CRS has been identified as a clinically significant, ontarget, off-tumor side effect of the CAR T cell therapies used for treatment of malignancies. Characteristics of CRS include fever, headache, encephalopathy, hypotension, tachycardia, capillary leak, and multi-organ dysfunction [9]. The reported incidence of CRS after CAR T cell therapy ranges from 37 to $93 \%$, with 1 to $46 \%$ of patients experiencing the severe or life-threatening form [9]. Serum levels of inflammatory cytokines are elevated, particularly IL-6 [9]. The severity of symptoms may correlate with the serum cytokine concentrations and the duration of exposure to the inflammatory cytokines [9].

On August 30, 2017, the U.S. Food and Drug Administration approved tocilizumab for the treatment of severe or life-threatening CAR T cell-induced CRS in adults and in pediatric patients 2 years of age and older [10], and tocilizumab is also approved for CAR T-induced severe or life-threatening CRS in the EU and certain other countries [11]. The approval of tocilizumab was based on a retrospective analysis of data for patients treated with tocilizumab who developed CRS after treatment with tisagenlecleucel or axicabtagene ciloleucel in prospective clinical trials [12].

\section{Hypothesis of physiological role of IL-6 in COVID-19}

Though there are many things that have not yet revealed, COVID-19 shows acute respiratory illness with fever, loss of smell and taste, and respiratory symptoms, such as cough and shortness of breath as common symptoms caused by SARS-CoV-2 [13]. A striking feature of severe COVID-19 is the rapid progression of respiratory failure which is acute respiratory distress syndrome (ARDS) soon after the onset of dyspnea and hypoxemia due to lymphocyte infiltration into interstitial and alveolar spaces [14, 15]. Severe COVID-19 could also lead to acute coronary syndromes (ACS), kidney, and liver injury, in addition to vasculitis, coagulopathy, and shock [16-21]. These organ failures may be associated with a CRS characterized by high fevers, thrombocytopenia, hyperferritinemia, and elevation of other inflammatory markers including $\mathrm{C}$-reactive protein (CRP).
Unraveling the therapeutic potential of IL-6 signal inhibitors for COVID-19 is a matter of their mode of action corroborated by data of IL- 6 signal inhibitors in various diseases since COVID-19 has similar symptoms as inflammatory and autoimmune diseases where IL-6 signal inhibitors have already shown. For example, in the randomized double-blind placebo-controlled study (RCT/PBO) for sJIA, tocilizumab significantly improved systemic features including fever and rash and laboratory features including CRP, anemia thrombocytosis, and hyperferritinemia [22]. In RCT/PBO for RA, tocilizumab and sarilumab significantly improved fatigue, pain, and laboratory features $[23,24]$. In $\mathrm{RCT} / \mathrm{PBO}$ for SSc, regarding the mean change in forced vital capacity which was the secondary endpoint, tocilizumab performed better than placebo, suggesting a potentially clinically important effect of tocilizumab on the preservation of lung function $[25,26]$. In RCT/PBO for GCA, over half of patients treated with tocilizumab could achieve sustained remission without glucocorticoid which is free from vasculitis-related symptoms including pain, vision loss, and stroke [27]. For ACS, in RCT/PBO, tocilizumab significantly reduced high-sensitivity CRP and highsensitivity troponin $T$, encouraging further trials to assess the potential effects of IL-6 inhibition on clinical outcomes in ACS [28].

\section{Elevation of IL-6 in COVID-19}

In inflammatory condition, IL-6 is well-known to elevate, implicating that CRP which is one of the surrogate markers of IL-6 elevation allows us to detect that IL-6mediated inflammation occurs in our body [4]. Since IL6 is released by immune cells including macrophage and $\mathrm{T}$ cells, they are activated by virus or bacteria or other immune cells [2-4]. IL-6 acts like a messenger to activate other immune cells to fight the infection [3, 4]. Indeed, in patients with COVID-19, it has been reported that IL-6 level is significantly elevated and associated with adverse clinical outcomes including severity and mortality of COVID-19 in published papers and preprint papers [29-31]. Based on these facts, IL-6 or CRP, which is its surrogate marker can support physicians, together with other tests and vital signs, to decide if intensive care therapy is necessary, or if a specific therapy (e.g. mechanical ventilation) should be started or 
intensified and how long intensive care therapy is needed. In the USA, FDA declared the emergency use authorization for use of IL-6 immunoassay for COVID-19 patients [32]. The assay is used to assist in identifying severe inflammatory response in patients with confirmed COVID-19 illness to aid in determining the risk of intubation with mechanical ventilation, in conjunction with clinical findings and the results of other laboratory testing [32]. And, in the Chinese Clinical Guidance for COVID19 Pneumonia Diagnosis and Treatment (7th Edition), published by China National Health Commission on March 4, 2020, IL-6 is the part of measurements [33]. Moreover, the Italian Society of Infectious and Tropical Diseases (Handbook for the care of people with disease COVID-19, Edition 2.0) mentions that IL-6 is the central mediator of cytokine release syndrome toxicity and IL-6 could help to identify most severe COVID-19 patients who could benefit from further therapy [34].

\section{REAL world experience with IL-6 blockade in COVID-19 pneumonia}

In the beginning of the world pandemic, physicians in China initiated the off-label use of tocilizumab in the treatment of COVID-19 pneumonia. In February 2020, 21 patients with severe or critical COVID-19 pneumonia were treated with tocilizumab $400 \mathrm{mg}$ IV plus standard of care (SOC) [35]. The average age of the patients was $56.8 \pm 16.5$ years, ranging from 25 to 88 years. Seventeen patients $(81.0 \%)$ were assessed as severe, and 4 patients (19.0\%) were assessed as critical. Most patients (85.0\%) were presented with lymphopenia. CRP levels were increased in all 20 patients evaluated (mean $75.06 \pm 66.80$ $\mathrm{mg} / \mathrm{L}$ ). The median procalcitonin (PCT) value was 0.33 $\pm 0.78 \mathrm{ng} / \mathrm{mL}$, and only 2 of 20 patients $(10.0 \%)$ were presented with an abnormal value. Mean IL-6 level before tocilizumab was $132.38 \pm 278.54 \mathrm{pg} / \mathrm{mL}$ (normal < $7 \mathrm{pg} / \mathrm{mL}$ ). SOC is consisted of lopinavir, methylprednisolone, other symptom relievers, and oxygen therapy as recommended by the Diagnosis and Treatment Protocol for Novel Coronavirus Pneumonia (Trial Version 6) (China National Health Commission 2020) [36]. All 21 patients had received routine SOC treatment for a week before deteriorating with sustained fever, hypoxemia, and chest computed tomography (CT) image worsening. Eighteen patients $(85.7 \%)$ received tocilizumab once, and 3 patients (14.3\%) had a second dose due to fever within $12 \mathrm{~h}$. According to the authors, after tocilizumab treatment, fever returned to normal, and all other symptoms improved remarkably. Fifteen of the 20 patients (75.0\%) had lowered their oxygen intake, and 1 patient needed no oxygen therapy. CT scans showed significant remission of opacities in both lungs in 19 of 21 patients (90.5\%) after treatment with tocilizumab. The percentage of lymphocytes in peripheral blood, which was decreased in 17 of 20 patients $(85 \%)$ before treatment (mean 15.52 $\pm 8.89 \%$ ), returned to normal in 10 of 19 patients (52.6\%) on the fifth day after treatment. Abnormally elevated CRP decreased significantly in 16 of 19 patients (84.2\%). No adverse drug reactions and no subsequent pulmonary infections were reported. Nineteen patients (90.5\%) were discharged at the time of the report, including 2 critical patients. There were no deaths among the 21 treated patients. The study authors concluded that tocilizumab is an effective treatment for patients with severe COVID-19 pneumonia [35].

CORIMUNO-TOCI which is an investigator initiated study is part of CORIMUNO-19, a French multi-center, open-label, platform study examining the safety and efficacy of immunomodulators in COVID-19 [37]. The study randomized 129 non-ICU patients with moderatesevere pneumonia (requiring supplemental oxygen) 1:1 planned to receive 1 or 2 doses of tocilizumab $8 \mathrm{mg} / \mathrm{kg}+$ $\mathrm{SOC}$ vs SOC alone. The primary composite outcome was the need for ventilation (non-invasive or mechanical) or death by day 14. As stated in the press release from 27 April regarding this composite endpoint, a significantly lower proportion of patients in the tocilizumab required either ventilation (non-invasive or mechanical) or died by day 14 [37].

TOCIVID-19 is the first and largest study on tocilizumab authorized by the Italian Medicines Agency (AIFA) $[38,39]$. The primary analysis concerns 301 patients registered for the phase 2 study (in $20 \mathrm{~h}$ between 19 and 20 March), and 920 patients subsequently registered between 20 and 24 March, coming from 185 clinical centers distributed throughout Italy. These patients had all been hospitalized due to a picture of pneumonia that occurred during coronavirus infection, and showed signs of respiratory failure. On the other hand, patients intubated for more than $24 \mathrm{~h}$ were excluded from this analysis and will be further investigated. The group of 920 patients was included in the analysis with the aim of confirming the results observed in the phase 2 study. Due to the limited initial availability of the drug, and the very rapid request from the centers, in both groups, only $60 \%$ of the patients were treated with tocilizumab, in some cases even at a significant time after registration. Furthermore, probably due to a selection made in the centers, the treated patients were clinically worse than the untreated ones, with more severe respiratory insufficiency and more intensive forms of respiratory assistance. Over the next 30 days, 67 deaths were recorded in the phase 2 study. As defined by the protocol [38], the primary analysis was conducted on the 14 and 30 day lethality rate. In particular, at 14 days, the lethality rate reported in phase 2 was $18.4 \%$, considering all patients, and $15.6 \%$, considering only those who received the drug, both lower, but not statistically significantly, versus 
$20 \%$ expected a priori on the basis of data provided by the Istituto Superiore di Sanità. On the other hand, the results are statistically significant in the 30-day analysis, when the lethality values are $22.4 \%$ in all patients and $20.0 \%$ in the treated only compared to $>30 \%$ expected a priori. The validation group of 920 patients is characterized by a much better prognosis than in phase 2, particularly with regards to patients not treated with tocilizumab. In fact, at 14 days, lethality is $11.4 \%$ in all patients and $10.9 \%$ in treated patients, and at 30 days, $18.4 \%$ in all patients and $20.0 \%$ in treated patients. On one hand, these results confirm those reported in phase 2 , but on the other, they introduce a necessary element of caution in the interpretation. The analysis of adverse events conducted in the joint population of 708 treated patients did not show relevant signs of specific toxicity, other than the expected adverse events in the underlying pathological condition. The study authors concluded that the TOCIVID-19 study, despite the limitations of a single-arm study, made more complex by the rapid enrollment and the corresponding limited availability of the drug suggests that tocilizumab may significantly reduce mortality to 1 month, but that its impact is less relevant on early mortality [39].

In Italy, another large observational cohort study (TESEO study) was conducted and published by Giovanni $\mathrm{G}$ et al. Five hundred forty-four patients had severe COVID-19 pneumonia and were included in this study [40]. Fifty-seven (16\%) of 365 patients in the standard care group needed mechanical ventilation, compared with 33 (18\%) of 179 patients treated with tocilizumab intravenous and subcutaneous. Seventy-three (20\%) patients in the standard care group died, compared with 13 (7\%; $p<$ 0.0001) patients treated with tocilizumab. After adjustment for sex, age, recruiting centre, duration of symptoms, and SOFA score, tocilizumab treatment was associated with a reduced risk of invasive mechanical ventilation or death (adjusted hazard ratio $0.61,95 \%$ CI $0.40-0.92 ; p=0.020$ ). Twenty-four (13\%) of 179 patients treated with tocilizumab were diagnosed with new infections, versus $14(4 \%)$ of 365 patients treated with standard of care alone $(p<0.0001)$.

Based on these reports, on March 3, 2020, China's National Health Commission included tocilizumab IV in the 7th updated diagnosis and treatment plan for COVID-19, making it the first of many countries to add tocilizumab in their national treatment guidance [33]. Other countries that have included tocilizumab in COVID-19 treatment guidelines include Italy, Spain, Greece, Switzerland, Ireland, Russia, Poland, Qatar, Lebanon, Egypt, Israel, and Japan.

Since another IL-6 receptor inhibitor, sarilumab is only marketed in subcutaneous formulation, and no reports from real-world data have been presented as far as it was searched as of 2 June 2020.

\section{On-going and planned industory sponsored trials}

Despite the millions of cases and hundreds of thousands of deaths that have occurred in this COVID-19 pandemic, high standard clinical trials such as RCT/PBO should be conducted in order to evaluate efficacy and safety profile of candidate therapeutics. Although it is used to take a while to conduct trials and review documentations for drug application, this urgent task for health authorities and industries all over the world could transform them more agile and cooperative in order to deliver scientifically authorized therapeutics for patients who need treatment. As shown in Table 1, seven industry sponsored trials of two IL-6 receptor inhibitors are on-going and planned for COVID-19 pneumonia patients.

On 27 April 2020, Sanofi and Regeneron provided update on U.S. phase $2 / 3$ adaptive designed trial in hospitalized COVID-19 patients [48]. The randomized phase 2 portion of the trial compared intravenously administered sarilumab higher dose $(400 \mathrm{mg})$, sarilumab lower dose (200 mg), and placebo. It assessed 457 hospitalized patients, who were categorized at baseline as having either "severe" illness (28\% of patients), "critical" illness (49\% of patients), or "multi-system organ dysfunction" (MSOD) (23\% of patients). Patients were classified as "severe" if they required oxygen supplementation without mechanical or high-flow oxygenation; or "critical" if they required mechanical ventilation or high-flow oxygenation or required treatment in an intensive care unit. Preliminary analysis of the phase 2 portion of the trial demonstrated that sarilumab rapidly lowered CRP, a key marker of inflammation, meeting the primary endpoint. Baseline levels of IL-6 were elevated across all treatment arms, with higher levels observed in "critical" patients compared to "severe" patients. Additionally, no new safety findings were observed with the use of sarilumab in COVID-19 patients [48].

On 2 July 2020, Sanofi and Regeneron announced the U.S. phase 3 trial (NCT04315298) of sarilumab $400 \mathrm{mg}$ in COVID-19 patients requiring mechanical ventilation which did not meet its primary and key secondary endpoints when sarilumab was added to the best supportive care compared to the best supportive care alone (placebo) [46, 49]. Minor positive trends were observed in the primary pre-specified analysis group (critical patients on sarilumab $400 \mathrm{mg}$ who were mechanically ventilated at baseline) that did not reach statistical significance, and these were countered by negative trends in a subgroup of critical patients who were not mechanically ventilated at baseline. In the primary analysis group, adverse events were experienced by $80 \%$ of sarilumab patients and $77 \%$ of placebo patients. Serious adverse events that occurred in at least $3 \%$ of patients and more frequently among sarilumab patients were multi organ dysfunction syndrome ( $6 \%$ sarilumab, $5 \%$ placebo) and 


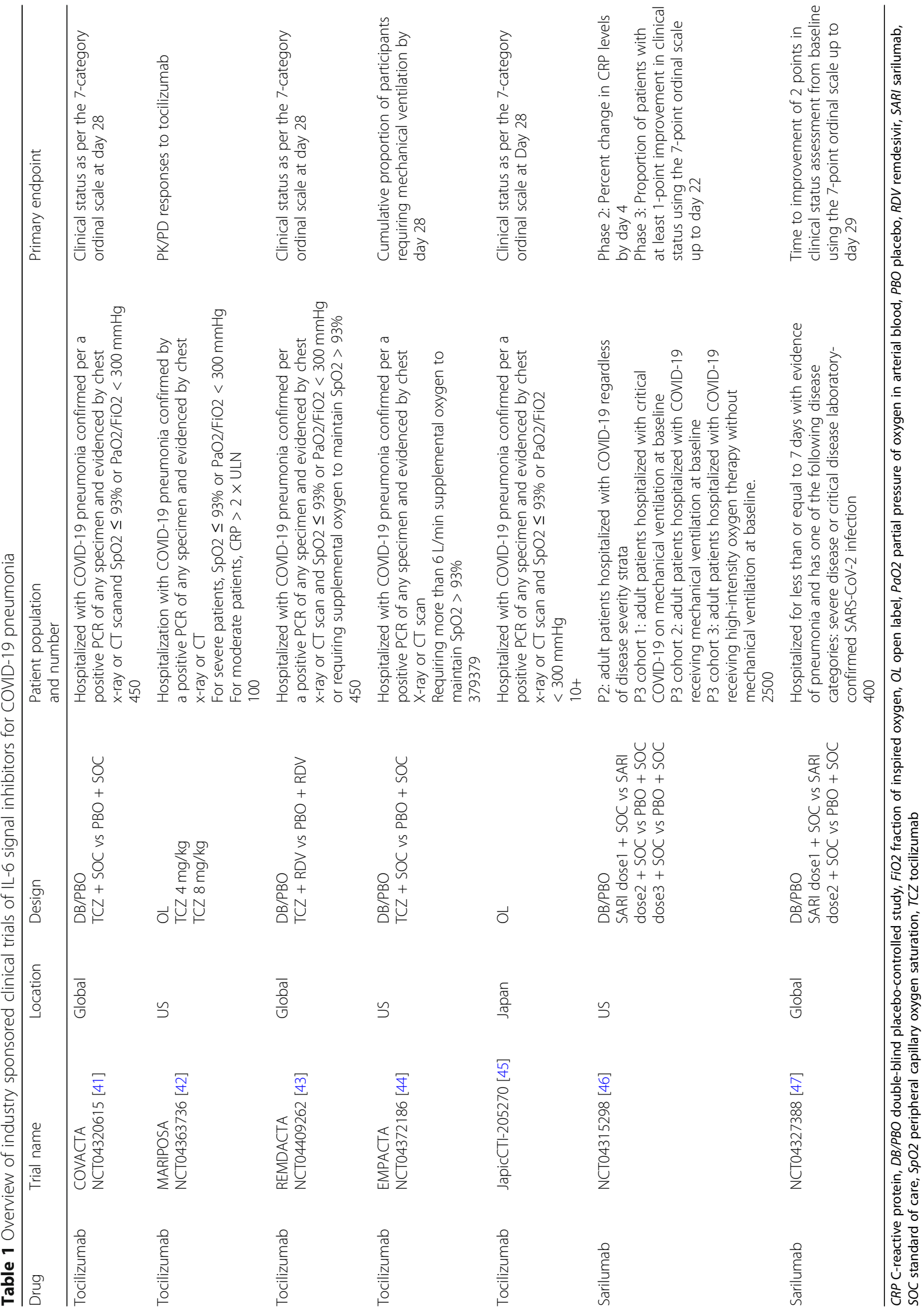


hypotension ( $4 \%$ sarilumab, $3 \%$ placebo). Based on the results, the U.S.-based trial has been stopped, including in a second cohort of patients who received a higher dose of sarilumab $(800 \mathrm{mg})$. A separate trial outside of the USA in hospitalized patients with severe and critical COVID-19 using a different dosing regimen [47] is ongoing. Although preliminary results were also presented in the press release, the details of results should be reviewed in future publications since the study is ongoing.

\section{Conclusions}

There is currently only a drug licensed for the treatment of patients with COVID-19. Given physiological roles of IL- 6 in inflammatory conditions and the data from real world outlined above, IL- 6 signal inhibitors, along with SOC treatment, could provide efficacy, offering the potential to treat COVID-19 in hospitalized populations more effectively than current SOC alone. Extensive safety data have previously been generated on the use of IL-6 signal inhibitors in other indications. Therefore, ongoing and planned placebo-controlled studies in combination with SOC and others to assess safety and efficacy of IL-6 signal inhibitors in hospitalized patients with severe COVID-19 pneumonia will be warranted to address the high unmet need and burden of disease in this severely ill population.

\begin{abstract}
Abbreviations
ACS: Acute coronary syndromes; AOSD: Adult-onset Still's disease; ARDS: Acute respiratory distress syndrome; C3: Complement 3; CAR: Chimeric antigen receptor; CoV: Coronavirus; COVID-19: Coronavirus disease 2019; CRP: C-reactive protein; CRS: Cytokine-release syndrome; CT: Computed tomography; DB/PBO: Double-blind placebo controlled study; FiO2: Fraction of inspired oxygen; GCA: Giant cell arteritis; gp130: Glycoprotein 130; ICU: Intensive care unit; IL-6: Interleukin-6; IL-6R: Interleukin-6 receptor; IV: Intravenous; NT-ProBNP: N-terminal pro- B-type natriuretic peptide; OL: Open label; PaO2: Partial pressure of oxygen in arterial blood; PBO: Placebo; RA: Rheumatoid arthritis; RCT/PBO: Randomized double blind placebo controlled study; RDV: Remdesivir; SAA: Serum amyloid A; SARI: Sarilumab; SARS: Severe acute respiratory syndrome; sJIA: Systemic juvenile idiopathic arthritis; SOC: Standard of care; SpO2: Peripheral capillary oxygen saturation; pJIA: Polyarticular juvenile idiopathic arthritis;

TAK: Takayasu arteritis; TCZ: Tocilizumab
\end{abstract}

\section{Acknowledgements}

Not applicable

Author's contributions

$\mathrm{MH}$ wrote and approved the final manuscript

\section{Funding}

Not applicable

Availability of data and materials

Not applicable

Ethics approval and consent to participate

Not applicable

Consent for publication

Not applicable

\section{Competing interests}

$\mathrm{MH}$ is an employee of Chugai Pharmaceutical Co., Ltd.

Received: 28 June 2020 Accepted: 7 July 2020

Published online: 05 October 2020

\section{References}

1. Kishimoto T, Ishizaka K. Regulation of antibody response in vitro. VII. Enhancing soluble factors for IgG and IgE antibody response. J Immunol. 1973;111:1194-205.

2. Choy EH, De Benedetti F, Takeuchi T, Hashizume M, John MR, Kishimoto T. Translating IL-6 biology into effective treatments. Nat Rev Rheumatol. 2020; 16(6):335-45.

3. Hashizume M, Tan SL, Takano J, Ohsawa K, Hasada I, Hanasaki A, Ito I, Mihara M, Nishida K. Tocilizumab, a humanized anti-IL-6R antibody, as an emerging therapeutic option for rheumatoid arthritis: molecular and cellular mechanistic insights. Int Rev Immunol. 2015;34(3):265-79.

4. Garbers C, Heink S, Korn T, Rose-John S. Interleukin-6: designing specific therapeutics for a complex cytokine. Nat Rev Drug Discov. 2018;17(6):395-412.

5. Hashizume M, Mihara M. Atherogenic effects of TNF-a and IL-6 via upregulation of scavenger receptors. Cytokine. 2012 Jun;58(3):424-30.

6. Suzuki M, Hashizume M, Yoshida H, Mihara M. Anti-inflammatory mechanism of tocilizumab, a humanized anti-IL-6R antibody: effect on the expression of chemokine and adhesion molecule. Rheumatol Int. 2010 Jan; 30(3):309-15.

7. Welsh P, Tuckwell K, McInnes I, Sattar N. Effect of IL-6 Receptor Blockade on High-Sensitivity Troponin T and NT-proBNP in Rheumatoid Arthritis. Atherosclerosis. 2016 Nov:254:167-71.

8. Karhu J, Ala-Kokko TI, Vuorinen T, Ohtonen P, Julkunen I, Syrjälä HT. Interleukin-5, interleukin-6, interferon induced protein-10, procalcitonin and C-reactive protein among mechanically ventilated severe communityacquired viral and bacterial pneumonia patients. Cytokine. 2019 Jan;113: 272-6.

9. Santomasso B, Bachier C, Westin J, Rezvani K, Shpall EJ. The Other Side of CAR T-Cell Therapy: Cytokine Release Syndrome, Neurologic Toxicity, and Financial Burden. Am Soc Clin Oncol Educ Book. 2019;39:433-44.

10. FDA approves tisagenlecleucel for B-cell ALL and tocilizumab for cytokine release syndrome https://www.fda.gov/drugs/resources-informationapproved-drugs/fda-approves-tisagnlecleucel-b-cell-all-and-tocilizumabcytokine-release-syndrome Accessed 27th April 2020.

11. CHMP positive opinion for use of tocilizumab in CRS induced by CAR-T therapy https://www.ema.europa.eu/en/documents/smop/chmp-postauthorisation-summary-positive-opinion-roactemra_en-3.pdf Accessed 12th June 2020.

12. Le RQ, Li L, Yuan W, Shord SS, Nie L, Habtemariam BA, Przepiorka D, Farrell AT, Pazdur R. FDA Approval Summary: Tocilizumab for Treatment of Chimeric Antigen Receptor T Cell-Induced Severe or Life-Threatening Cytokine Release Syndrome. Oncologist. 2018;23(8):943-7.

13. Menni, C, Valdes A.M, Freidin MB, Sudre CH, Nguyen LH, Drew DA, Ganesh S, Varsavsky T, Cardoso MJ, El-Sayed Moustafa, et al. Real-time tracking of self-reported symptoms to predict potential COVID-19. Nat Med. 2020; https://doi.org/10.1038/s41591-020-0916-2. Advance online publication. https://doi.org/10.1038/s41591-020-0916-2.

14. Berlin DA, Gulick RM, Martinez FJ. Severe Covid-19. N Engl J Med. 2020. doi: https://doi.org/10.1056/NEJMcp2009575. Online ahead of print.

15. Zhang Y, Gao Y, Qiao L, Wang W, Chen D. Inflammatory Response Cells During Acute Respiratory Distress Syndrome in Patients With Coronavirus Disease 2019 (COVID-19). Ann Intern Med. 2020 Apr 13:L20-0227. doi: https://doi.org/10.7326/L20-0227. Online ahead of print.

16. Guo T, Fan Y, Chen M, Wu X, Zhang L, He T, Wang H, Wan J, Wang X, Lu Z. Cardiovascular implications of fatal outcomes of patients with coronavirus disease 2019 (COVID-19). JAMA Cardiol. 2020 Mar 27:e201017. doi: https://doi.org/10.1001/jamacardio.2020.1017. Online ahead of print.

17. Huang C, Wang Y, Li X, Ren L, Zhao J, Hu Y, Zhang L, Fan G, Xu J, Gu X, et al. Clinical features of patients infected with 2019 novel coronavirus in Wuhan, China. Lancet. 2020;395:497-506.

18. Zhang C, Shi L, Wang FS. Liver injury in COVID-19: management and challenges. Lancet Gastroenterol Hepatol. 2020;5(5):428-30.

19. Verdoni L, Mazza A, Gervasoni A, Martelli L, Ruggeri M, Ciuffreda M, Bonanomi E, D'Antiga L. An outbreak of severe Kawasaki-like disease at the 
Italian epicentre of the SARS-CoV-2 epidemic: an observational cohort study. Lancet. 2020;395(10239):1771-8.

20. The Lancet Haematology. COVID-19 coagulopathy: an evolving story. Lancet Haematol. 2020 Jun;7(6):e425. doi: https://doi.org/10.1016/S23523026(20)30151-4.

21. Bhatraju PK, Ghassemieh BJ, Nichols M, Kim R, Jerome KR, Nalla AK, Greninger AL, Pipavath S, Wurfel MM, Evans L, et al. Covid-19 in critically ill patients in the Seattle region — case series. N Engl J Med. 2020;382(21): 2012-22.

22. De Benedetti F, Brunner HI, Ruperto N, Kenwright A, Wright S, Calvo I, Cuttica R, Ravelli A, Schneider R, Woo P, et al. Randomized Trial of Tocilizumab in Systemic Juvenile Idiopathic Arthritis. N Engl J Med. 2012; 367(25):2385-95.

23. Townes $S V$, Furst $D E$, Thenkondar A. The impact of tocilizumab on physical function and quality of life in patients with rheumatoid arthritis: a systematic literature review and interpretation. Open Access Rheumatol. 2012:4:87-92.

24. Strand V, Reaney M, Chen Cl, Proudfoot CW, Guillonneau S, Bauer D, Mangan E, Graham NM, van Hoogstraten H, Lin Y, et al. Sarilumab improves patient-reported outcomes in rheumatoid arthritis patients with inadequate response/intolerance to tumour necrosis factor inhibitors. RMD Open. 2017; 3(1):e000416.

25. Khanna $D$, Denton $C P$, Jahreis $A$, van Laar JM, Frech $T M$, Anderson ME, Baron M, Chung L, Fierlbeck G, Lakshminarayanan S, et al. Safety and efficacy of subcutaneous tocilizumab in adults with systemic sclerosis (faSScinate): a phase 2, randomised, controlled trial. Lancet. 2016 Jun 25; 387(10038):2630-40.

26. Khanna D, L.C., Kuwana M, Allanore Y, Batalov A, Butrimiene I, Carreira P, Matucci Cerinic M, Distler O, Kaliterna DM, Mihai C, et al. Efficacy and Safety of Tocilizumab for the Treatment of Systemic Sclerosis: Results from a Phase 3 Randomized Controlled Trial Arthritis Rheumatol. $2018: 70$ (suppl 10).

27. Stone JH, Tuckwell K, Dimonaco S, Klearman M, Aringer M, Blockmans D, Brouwer E, Cid MC, Dasgupta B, Rech J, et al. Trial of Tocilizumab in GiantCell Arteritis. N Engl J Med. 2017;377:317-28.

28. Kleveland O, Kunszt G, Bratlie M, Ueland T, Broch K, Holte E, Michelsen AE, Bendz B, Amundsen BH, Espevik T, et al. Effect of a single dose of the interleukin-6 receptor antagonist tocilizumab on inflammation and troponin T release in patients with non-ST-elevation myocardial infarction: a doubleblind, randomized, placebo-controlled phase 2 trial. Eur Heart J. 2016;37(30): 2406-13.

29. Chen L, Liu HG, Liu W, et al. Analysis of clinical features of 29 patients with 2019 novel coronavirus pneumonia. Zhonghua Jie He He Hu Xi Za Zhi. 2020:43(0):E005

30. Diao B, Wang C, Tan Y, et al. Reduction and functional exhaustion of T Cells in patients with coronavirus disease 2019 (COVID-19). medRxiv. 2020. doi: https://doi.org/10.1101/2020.02.18.20024364. Accessed 2th June 2020.

31. Wu C, Chen X, Cai Y, Xia J, Zhou X, Xu S, Huang H, Zhang L, Zhou X, Du C et al. Risk factors associated with acute respiratory distress syndrome and death in patients with coronavirus disease 2019 pneumonia in wuhan china. JAMA Intern Med. 2020 Mar 13:e200994. doi: https://doi.org/10.1001/ jamainternmed.2020.0994. Online ahead of print

32. FDA Emergency Use Authorization Elecsys IL-6 https://www.fda.gov/ media/138596/download Accessed 7th June 2020.

33. Chinese Clinical Guidance for COVID-19 Pneumonia Diagnosis and Treatment (7th Edition) http://kjfy.meetingchina.org/msite/news/show/ $\mathrm{cn} / 3337 . \mathrm{html}$ Accessed 2th June 2020.

34. Italian Society of Infectious and Tropical Diseases (Handbook for the care of people with disease COVID-19, Edition 2.0, March 13, 2020) http://www. simit.org/medias/1569-covid19-vademecum-13-03-202.pdf Accessed 2th June 2020.

35. Effective Treatment of Severe COVID-19 Patients with Tocilizumab http:// www.chinaxiv.org/user/download.htm?id=30387 Accessed 2th June 2020.

36. Diagnosis and Treatment Protocol for Novel Coronavirus Pneumonia (Trial Version 6) (China National Health Commission 2020). http://www. kankyokansen.org/uploads/uploads/files/jsipc/protocol_V6.pdf Accessed 2th June 2020.

37. CORIMUNO-TOCI press release. https://www.aphp.fr/contenu/tocilizumabimproves-significantly-clinical-outcomes-patients-moderate-or-severe-covid-1 9. Accessed $27^{\text {th }}$ April 2020
38. TOCIVID-19 protocol. https://www.aifa.gov.it/documents/20142/1127901/ TOCIVID-19_Protocol_v1.3_18Marzo2020.pdf/6843930d-9f31-185d-9812-2 9f02ebebd76 Accessed 2th June 2020.

39. TOCIVID-19 press release. https://www.aifa.gov.it/documents/2 0142/1161351/TOCIVID-19_documenti.zip/ad89f0e3-09a6-fced-fd8a-d1251 dedfba4 Accessed 2th June 2020.

40. Guaraldi G, Meschiari M, Cozzi-Lepri A, Milic J, Tonelli R, Menozzi M, Franceschini E, Cuomo G, Orlando G, Borghi V, et al. Tocilizumab in patients with severe COVID-19: a retrospective cohort study. Lancet Rheumatol., Published Online June 24, 2020 10.1016/S2665-9913(20)30173-9.

41. NCT04320615 https://clinicaltrials.gov/ct2/show/NCT04320615 Accessed 2th June 2020.

42. NCT04363736 https://clinicaltrials.gov/ct2/show/NCT04363736 Accessed 2th June 2020.

43. NCT04409262 https://clinicaltrials.gov/ct2/show/NCT04409262 Accessed 3rd June 2020.

44. NCT04372186 https://clinicaltrials.gov/ct2/show/NCT04372186 Accessed 2th June 2020.

45. JapicCTI-205270 https://www.clinicaltrials.jp/cti-user/trial/ShowDirect. jsp?japicld=JapicCTI-205270 Accessed 2th June 2020.

46. NCT04315298 https://clinicaltrials.gov/ct2/show/NCT04315298 Accessed 6th July 2020.

47. NCT04327388 https://linicaltrials.gov/ct2/show/NCT04327388 Accessed 2th June 2020.

48. The update of sarilumab study in hospitalized COVID-19 patients. https:// www.sanoficom/en/media-room/press-releases/2020/2020-04-27-12-58-00 Accessed 2th June 2020

49. Sanofi and Regeneron provide update on Kevzara (sarilumab) Phase 3 U.S. trial in COVID-19 patients. https://www.sanofi.com/en/media-room/pressreleases/2020/2020-07-02-22-30-00 Accessed 6th July 2020

\section{Publisher's Note}

Springer Nature remains neutral with regard to jurisdictional claims in published maps and institutional affiliations.

Ready to submit your research? Choose BMC and benefit from:

- fast, convenient online submission

- thorough peer review by experienced researchers in your field

- rapid publication on acceptance

- support for research data, including large and complex data types

- gold Open Access which fosters wider collaboration and increased citations

- maximum visibility for your research: over $100 \mathrm{M}$ website views per year

At BMC, research is always in progress.

Learn more biomedcentral.com/submissions 